|EURE Vol $39 \mid$ N $^{\circ} \mathbf{1 1 8} \mid$ Septiembre $2013 \mid$ pp. 123-148 | artículos | OEURE

\title{
La ampliación del Metro en la periferia de Madrid (1999-2011)
}

\author{
Miguel A. Alonso-Neira. Universidad Rey Juan Carlos, Madrid, España. \\ Rocío Gallego-Losada. Universidad Rey Juan Carlos, Madrid, España. \\ Luis Pires-Jiménez. Universidad Rey Juan Carlos, Madrid, España.
}

RESUMEN | El crecimiento de población y empleo en la metrópoli de Madrid implica un aumento de la movilidad y de su complejidad. Este trabajo analiza cómo influye esta situación en el planeamiento de los transportes públicos del gobierno de Madrid, cuyo principal esfuerzo inversor se ha centrado desde 1999 en la ampliación de la red de Metro hacia los municipios que rodean la ciudad. El análisis de la eficiencia de estas ampliaciones ofrece los siguientes resultados: i) el menor coste de la inversión de metro ligero ha permitido reducir los problemas financieros de los gobiernos madrileños; y ii) la demanda por los nuevos servicios de transporte aumenta durante los primeros años, aunque desciende posteriormente. Estas conclusiones sugieren la complejidad de las decisiones económicas y políticas de estas ampliaciones, adaptadas a la evolución policéntrica y dispersa de Madrid.

PALABRAS ClAVE | áreas metropolitanas, modelos de transporte, movilidad.

ABSTRACT | The growth of population and jobs in the metropolis of Madrid means an increase in this city 's mobility and complexity. This paper analyzes how this situation affects the planning of public transports by the Government of Madrid, whose main investment effort since 1999 has focused on the expansion of the subway network to the municipalities surrounding the capital. The analysis of the efficiency of these extensions provides the following results: i) the lower cost of investment in the light rail has made it possible to reduce the financial problems of the governments of Madrid, and ii) the demand for the new transport services increases during the early years, although it descends later. These findings suggest the complexity of the economic and political decisions linked to these enlargements, which have been adapted to the Madrid's polycentric and scattered development.

KEY WORDS | metropolitan areas, transportation models, mobility.

Recibido el 4 de julio de 2011, aprobado el 20 de septiembre 2012

E-mail: Miguel Á. Alonso, miguelangel.alonso@urjc.es | Rocío Gallego, rocio.gallego@urjc.es | Luis Pires, luis.pires@urjc.es 


\section{Introducción}

Madrid es una de las regiones más dinámicas y modernas de España, lo que se manifiesta en un aumento de su población y una redistribución de esta desde el centro de la ciudad hacia zonas periféricas. ${ }^{1}$ De los casi 6,5 millones de habitantes de la región metropolitana de Madrid (RMM a partir de ahora) en 2011, hoy viven en la ciudad central 3,3 millones (1,1 millones en la Almendra Central y 2,2 millones en la Periferia Urbana), mientras que 2,7 millones viven en la Corona Metropolitana y solo medio millón en la Corona Regional. En las dos últimas décadas, la RMM se ha ido transformando desde un modelo monocéntrico, donde la capital tiene un papel predominante como núcleo poblacional y de empleo, hacia modelos mixtos con pautas de policentrismo y dispersión (Gallo, Garrido \& Vivar, 2010). Esta nueva estructura polinuclear implica que la ciudad central pierda peso relativo en términos demográficos y productivos, a la vez que se consolidan varios subcentros en los municipios de la Corona Metropolitana, agrupados a lo largo de las principales vías de circulación o corredores metropolitanos. ${ }^{2}$

En una estructura de ciudad polinuclear, los subcentros metropolitanos emergen como centros locales que desarrollan su propia actividad económica y generan su propia demanda de trabajo, convirtiéndose en núcleos de referencia económica y social para los territorios colindantes (Roca, Arellano \& Moix, 2011). En este sentido, aunque la ciudad de Madrid sigue conservando un importante rol de organización funcional de todo el sistema metropolitano, su relación con la periferia (Corona Metropolitana y Corona Regional) se va haciendo cada vez más dispersa y descentralizada como consecuencia del progresivo proceso de desconcentración de la población y del empleo de los últimos años.

Estas variaciones en la estructura del sistema metropolitano se traducen en cambios sustanciales en las pautas de movilidad entre la ciudad central y los subcentros poblacionales (movimientos radiales), y entre estos últimos y las poblaciones de su área de influencia (movimientos transversales). A su vez, las modificaciones en el reparto territorial de la población y en los flujos de movilidad laboral concomitantes dificultan que el transporte público sea una opción competitiva en zonas caracterizadas por una baja densidad de población (Monzón \& De la Hoz, 2006).

El presente trabajo analiza cómo los transportes del área metropolitana de Madrid se están adaptando a esta nueva y cambiante realidad. Particularmente, examina la situación de los municipios que rodean la ciudad de Madrid en la Corona Metropolitana, junto con el planeamiento de los transportes públicos del gobierno regional. Así, en primer lugar, considera la evolución de la RMM en términos de los cambios observados en la distribución territorial de la población y el empleo,

1 Madrid se divide en cuatro grandes áreas o coronas: i) la Almendra Central, delimitada por la autovía de circunvalación M-30; ii) la Periferia Urbana; iii) la Corona Metropolitana, que incluye los municipios más cercanos a la ciudad; y iv) la Corona Regional, que integra los municipios más alejados. Véase Figura 2 de este trabajo.

2 Madrid se divide en cuatro grandes áreas o coronas: i) la Almendra Central, delimitada por la autovía de circunvalación M-30; ii) la Periferia Urbana; iii) la Corona Metropolitana, que incluye los municipios más cercanos a la ciudad; y iv) la Corona Regional, que integra los municipios más alejados. Véase Figura 2 de este trabajo. 
procediendo a la caracterización de los subcentros ubicados en la Corona Metropolitana. Posteriormente, el segundo apartado repasa las principales inversiones de los gobiernos madrileños en transporte público que, desde 1999, se han centrado de manera especial en la ampliación de la red de Metro hacia algunas poblaciones situadas en esta misma franja de la metrópoli madrileña. El tercer apartado describe estas ampliaciones, que suponen la entrada de nuevas infraestructuras ferroviarias como el Metro Ligero, el tren unido a la red de Metro, o el tranvía. Finalmente, el último apartado analiza la eficiencia de las ampliaciones y de las nuevas infraestructuras ferroviarias, realizando un análisis del coste de la inversión y de la demanda de los nuevos servicios.

\section{El proceso de desconcentración de la población y el empleo en la Región Metropolitana de Madrid}

Entre 1990 y 2011 el peso demográfico del municipio de Madrid se ha reducido considerablemente desde $62,1 \%$ hasta $50,3 \%$ en el conjunto de la región, mientras que la población de la Corona Metropolitana ha aumentado significativamente su participación desde $34,3 \%$ hasta $41,7 \%$. En esta última, si bien es el sur metropolitano el que concentra de manera permanente un mayor porcentaje de la población empadronada (19,6\% entre 1990 y 2011), destacando los municipios de Móstoles, Fuenlabrada, Leganés y Getafe, son el oeste y el este metropolitanos los que han experimentado mayores incrementos relativos de población.

Respecto del empleo, mientras la ciudad central ha pasado de concentrar el 69,27\% del total de afiliados en alta a la Seguridad Social de la RMM en 1999, a $62,64 \%$ en 2011, la Corona Metropolitana ha aumentado su peso relativo desde $27,47 \%$ hasta $33,24 \%$ durante el mismo período. Dentro del anillo metropolitano, nuevamente es la zona sur la que concentra un mayor porcentaje de afiliados, situándose en el 11,5\% del total regional. Sin embargo, las mayores elevaciones relativas del empleo se observan en el oeste y el norte metropolitanos, en detrimento de la capital.

Pese a estos datos, el municipio de Madrid continúa ejerciendo el rol de ciudad central, al concentrar el 62,64\% del empleo de la región metropolitana, con la mitad de sus habitantes (50,3\%). A partir de los datos de movilidad entre el lugar de trabajo y el de residencia de los afiliados a la Seguridad Social correspondientes al año 2011, la Figura 1 muestra que 45,63\% de los trabajadores que habitan en la Corona Metropolitana (1.093.680) se desplazan a diario a la capital para desempeñar su actividad laboral, siendo especialmente relevantes los flujos procedentes del sur y del este metropolitano (229.732 y 114.691, respectivamente). Igualmente, $18 \%$ de los trabajadores empadronados en la ciudad de Madrid (1.247.439) desarrollan su labor profesional en el anillo metropolitano, desplazándose fundamentalmente hacia el norte (69.891), sur (59.948) y oeste (59.114) de la región. 
FIGURA 1 | Movilidad laboral entre la Corona Metropolitana y la ciudad de Madrid en 2011

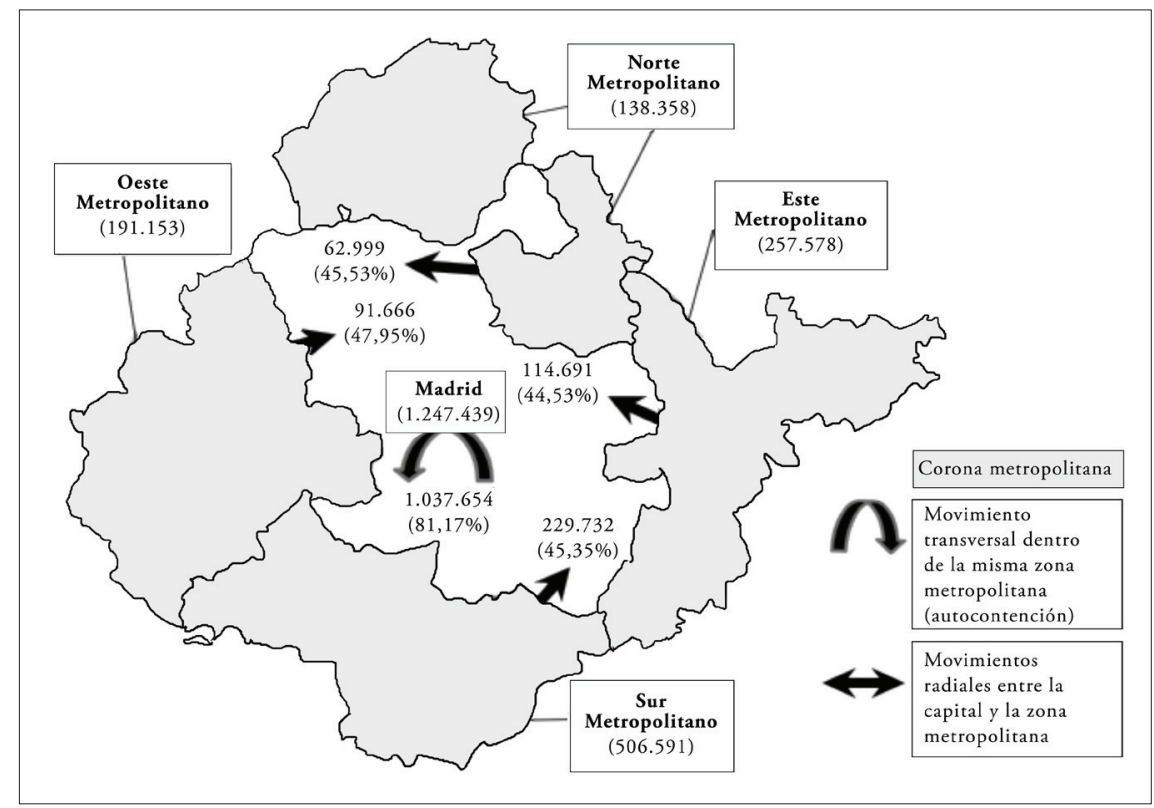

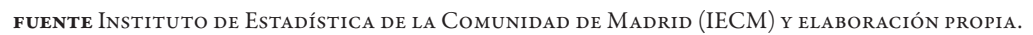

Respecto de la Corona Metropolitana, si bien el norte es la zona que presenta un mayor coeficiente de autocontención ${ }^{3}$ (43,93\% de sus 138.358 trabajadores residentes), más de la mitad de su población activa residente debe desplazarse a diario a la capital $(45,53 \%)$ o a otras áreas de la región metropolitana (8,70\%). Por el contrario, la zona con menor coeficiente de autocontención $(37,45 \%)$ es el oeste metropolitano, que presenta, sin embargo, una mayor dependencia de la ciudad central ( $47,95 \%$ de sus trabajadores residentes).

Aunque el municipio de Madrid continúa siendo el destino laboral de 45,63\% de los trabajadores que residen en la franja metropolitana, los coeficientes de autocontención relativos al norte, este y sur de la misma se sitúan en un valor promedio de $42,13 \%$. Esto implica que, en términos generales, los movimientos transversales que se producen dentro de cada una de las zonas que integran la Corona Metropolitana son equiparables a los movimientos radiales registrados entre cada una de ellas y la capital. En este sentido, la descentralización de los flujos de movilidad laboral es representativa de la consolidación de un modelo de desarrollo urbano policéntrico, en el que el sur metropolitano destaca como un importante núcleo poblacional (con más de 1.280 .000 habitantes) y de empleo (al retener $41,05 \%$ de sus 506.591 trabajadores residentes). 


\section{Los subcentros de la Corona Metropolitana}

Los subcentros se definen como núcleos poblacionales en el espacio metropolitano caracterizados no solo por tener una densidad de trabajadores sensiblemente superior a la de sus vecinos, sino sobre todo por ser capaces de ejercer una notable influencia sobre sus territorios colindantes (Aguirre \& Marmolejo, 2010). De este modo, pueden caracterizarse como localidades dentro de áreas de influencia específicas. En el caso de la Comunidad de Madrid, Méndez (2007) y Gallo, Garrido y Vivar (2010) consideran que las áreas de influencia son las propias autopistas o corredores metropolitanos a lo largo de los cuales se extienden y generan un conjunto de relaciones con otras localidades del entorno periférico.

Analizando los flujos laborales de la metrópoli madrileña entre 1981 y 2001, Solís (2008) establece que el cambio en la fisonomía de la región de Madrid se ha traducido en la configuración de una estructura policéntrica que en 2001 constaba de dieciséis subcentros. Alternativamente, Gallo, Garrido y Vivar (2010) identifican la presencia de doce subcentros adscritos a sus correspondientes corredores metropolitanos en los años 1996 y 2004. En un trabajo posterior, Gallo y Garrido (2012) elevan la cifra a trece en 2010, al incorporarse el municipio de Tres Cantos (vinculado al corredor metropolitano M-607) a la lista anterior.

Gallo, Garrido y Vivar (2010) caracterizan los subcentros de la región de Madrid procediendo a la definición de umbrales flexibles de densidad y concentración de empleo. Concretamente, calculan los porcentajes y la densidad de empleo (ocupados por $\mathrm{km}^{2}$ ) de cada uno de los municipios que integran la RMM utilizando los datos publicados por el Instituto de Estadística de la Comunidad de Madrid (IECM). Posteriormente, identifican los subcentros como aquellas localidades con una densidad laboral igual o superior a la media regional y que cuentan con una concentración de empleo igual o superior al 1\% del empleo total del sistema metropolitano. Sin embargo, como los propios autores señalan, la aplicación de este método implica una visión un tanto simplista del policentrismo. En lo concreto, sostienen que el grado de policentrismo no debería medirse de manera exclusiva en función de estos umbrales, sino sobre todo por la capacidad de los subcentros para incidir en las condiciones de población y empleo de los territorios de su entorno. Es decir, los subcentros deberían ser "elementos vertebradores de subsistemas urbanos dentro de la estructura general de la metrópoli” (Roca, Arellano \& Moix, 2011), constituyéndose en núcleos de referencia económica y social para las poblaciones colindantes.

En este sentido, Gallo y Garrido (2011) estudian el comportamiento de las áreas de influencia de los subcentros de la RMM analizando los desplazamientos laborales que tienen como origen cada uno de los corredores metropolitanos y sus diferentes destinos. Partiendo del cálculo de tres índices: i) de cohesión interna, ii) de dependencia funcional, y iii) de dispersión, estos autores identifican tres áreas de influencia con una alta incidencia de sus subcentros: los corredores metropolitanos Norte A-1, Este A-2 y Sur A-4. Por el contrario, los corredores A-42, A-5 y A-6 serían áreas de influencia con baja incidencia de sus subcentros. 
Análogamente, el Atlas de Movilidad Residencia-Trabajo de la Comunidad de Madrid (2010) analiza la influencia económica y funcional de cada uno de los municipios de la región metropolitana utilizando los datos de residencia y empleo proporcionados por la Tesorería General de la Seguridad Social (TGSS). A partir de estos datos, la ratio empleo/trabajadores residentes se define como el cociente entre el número de puestos de trabajo existentes en una determinada población y la cifra de empleados residentes en la misma. Esta ratio permite discriminar cuáles son los municipios de la RMM que se caracterizan por un mayor dominio de actividad y cuáles por un mayor dominio residencial. Así, valores superiores (inferiores) a la unidad denotarían la existencia de localidades con dominio de actividad (dominio residencial), es decir, con superávit (déficit) de puestos de trabajo en relación con su población activa residente.

El superávit de puestos de trabajo en los municipios con dominio de actividad quedaría cubierto por trabajadores residentes en otras localidades de la región metropolitana, especialmente en aquellas en las que existe un déficit de puestos de trabajo. De este modo, las diferencias entre el lugar de residencia y el lugar de trabajo darían cuenta de un importante flujo de desplazamientos -radiales y transversales- por motivos laborales dentro de la región metropolitana.

El Cuadro A1 del Apéndice muestra un conjunto de variables correspondientes a población, ocupación (concentración y densidad laboral) y actividad productiva de los municipios de la RMM con más de 40.000 habitantes. Al margen de la capital y de algunas localidades de la Corona Regional (Arganda del Rey, Collado Villalba y Valdemoro), todas estas poblaciones, agrupadas atendiendo a sus correspondientes corredores o áreas de influencia, se sitúan en la Corona Metropolitana.

Las columnas 3 y 4 muestran que, después de la ciudad central, las mayores concentraciones de población corresponden a los municipios del sur metropolitano: Alcorcón, Fuenlabrada, Getafe, Leganés y Móstoles. Estas localidades representan más del $14 \%$ de la población de la región metropolitana. A ellas pueden añadirse otros municipios situados en el este (Alcalá de Henares, Coslada y Torrejón de Ardoz), el norte (Alcobendas y San Sebastián de los Reyes) y el oeste (Las Rozas y Pozuelo de Alarcón) de la Corona Metropolitana. Por otro lado, las mayores densidades de población (columna 5) también corresponden a las localidades del sur y del este.

Respecto de las variables de ocupación (columnas 6 a 8), la mayor concentración de empleo recae nuevamente sobre las poblaciones del sur (12,32\% del total), destacando los municipios de Getafe, Leganés y Fuenlabrada. En línea con Gallo, Garrido y Vivar (2010), las localidades de la RMM que pueden definirse como subcentros según el criterio de localización de empleo se reducen a trece (Cuadro A1 y Figura 2): tres en el norte (Alcobendas, San Sebastián de los Reyes y Tres Cantos), cinco en el sur (Alcorcón, Fuenlabrada, Getafe, Leganés y Móstoles), tres en el este (Alcalá de Henares, Coslada y Torrejón de Ardoz) y dos en el oeste (Pozuelo de Alarcón y Las Rozas). Debe destacarse que cada corredor metropolitano dispone de al menos dos subcentros, exceptuando la autovía A4 y la carretera M607 -donde los únicos núcleos importantes corresponden a los municipios de Getafe y Tres Cantosy la autovía A3, que carece de subcentros definidos. 
FIGURA 2 | Subcentros de la región metropolitana en 2011 y ampliaciones de la red de Metro

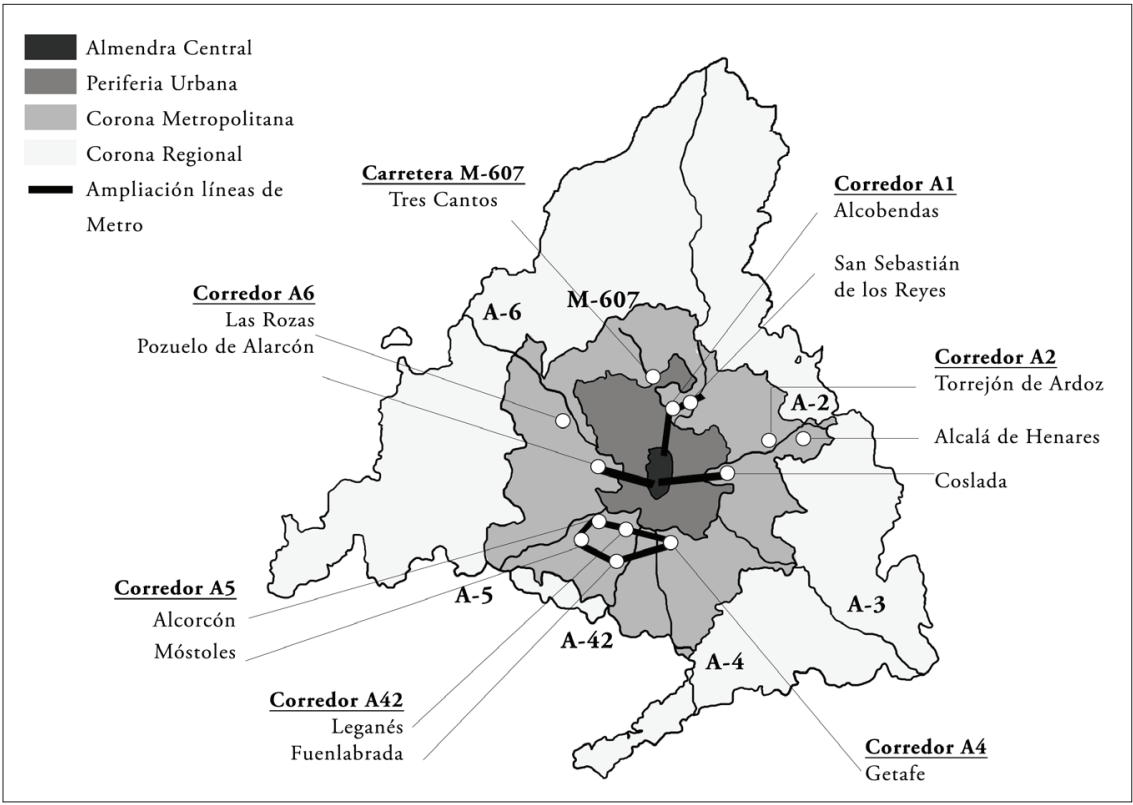

FUENTE ELABORACIÓN PROPIA.

Identificados los subcentros metropolitanos, se analiza la incidencia económica y funcional de estas poblaciones en sus respectivas áreas de influencia. Para ello se obtiene la ratio empleo/trabajadores residentes, con el objeto de determinar qué localidades pueden definirse como núcleos de atracción de trabajadores. Adicionalmente, se calcula qué porcentaje de empresas de la RMM con más de cien trabajadores ostenta cada uno de estos municipios.

Las columnas 9 y 10 muestran que ocho de los trece subcentros disponen de al menos $1,75 \%$ de las empresas de mayor tamaño de la región metropolitana. Además, puede observarse que el peso relativo de los respectivos parques empresariales se ha incrementado en los últimos años. Por último, las columnas 11 y 12 revelan que de los ocho subcentros con mayor relevancia empresarial, seis ostentan una ratio empleo/trabajadores residentes igual o superior a la unidad (Alcobendas, San Sebastián de los Reyes y Tres Cantos en el norte; Pozuelo de Alarcón y Las Rozas en el oeste, y Getafe en el sur). En estos municipios, el dominio de actividad también se ha incrementado en los últimos años.

Los resultados obtenidos serían consistentes con las cifras de los Gráficos 1 y 2 extraídas del Atlas de Movilidad Residencia-Trabajo de la Comunidad de Madrid (2010). Así, el Gráfico 1 muestra que, por lo general, los subcentros con las mayores ratios empleo/trabajadores residentes serían los principales receptores de trabajadores procedentes de otras zonas de la región metropolitana, especialmente de la 
capital. Este sería el caso de Alcobendas, Pozuelo, Las Rozas, San Sebastián de los Reyes y Getafe. Por el contrario, el Gráfico 2 refleja que las principales poblaciones con mayor número de trabajadores residentes que deben desplazarse hacia otras localidades de la RMM corresponden a los subcentros del sur y del este que, por lo general, presentan unas ratios empleo/trabajadores residentes inferiores a la unidad.

GRÁFICO 1 | Poblaciones con más trabajadores que proceden de otras zonas de la RMM

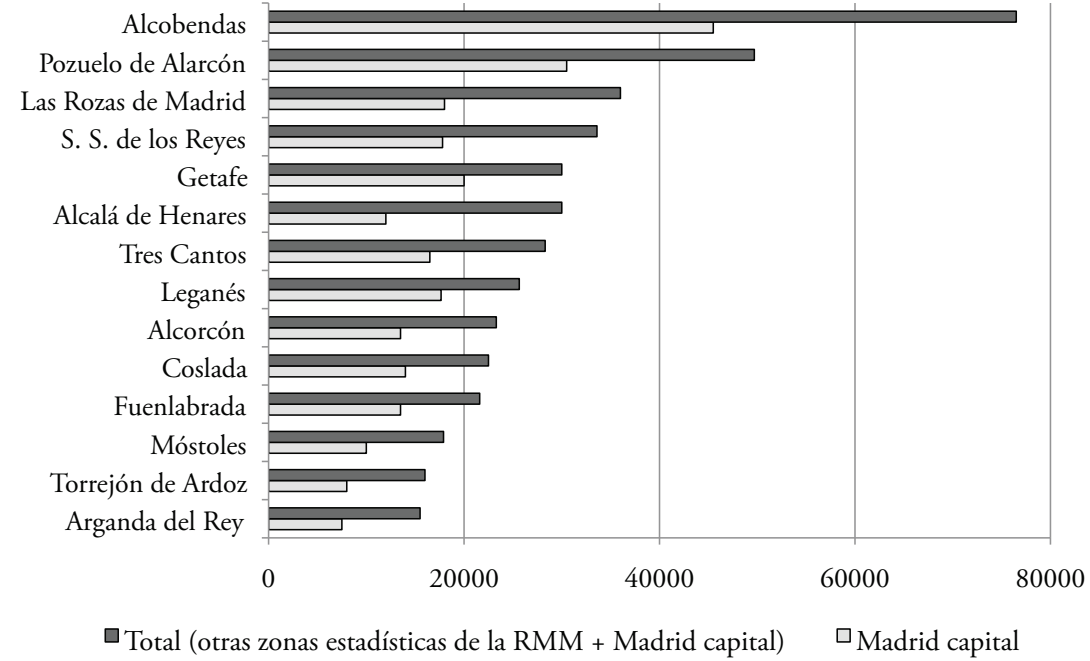

GRÁfICO 2 | Poblaciones con más trabajadores residentes que deben desplazarse hacia otras zonas de la RMM

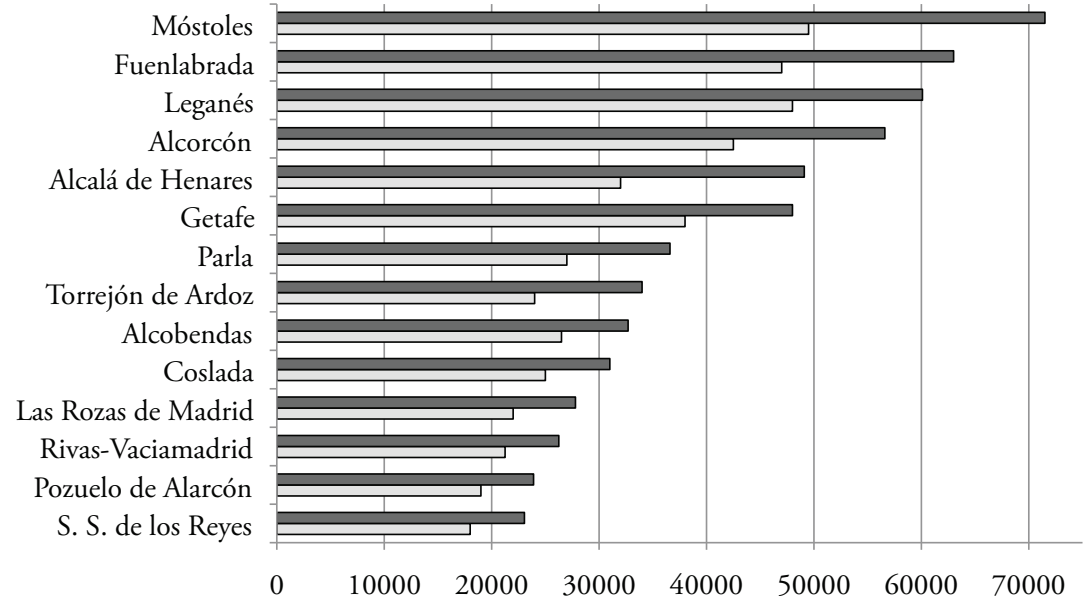

口Total (otras zonas estadísticas de la RMM + Madrid capital) $\quad \square_{\text {Madrid capital }}$ 
Por último, el Gráfico 3 revela que el mayor flujo de desplazamientos transversales por motivos laborales se produce entre los subcentros del sur metropolitano. Así, los trabajadores vinculados a estos municipios que deben desplazarse a diario hacia otras localidades de su misma área de influencia ascienden a más de 200.000, como puede apreciarse en la Figura 1 de este trabajo.

\section{GRÁfico 3 | Poblaciones con mayor número de desplazamientos transversales por motivos laborales de la RMM}

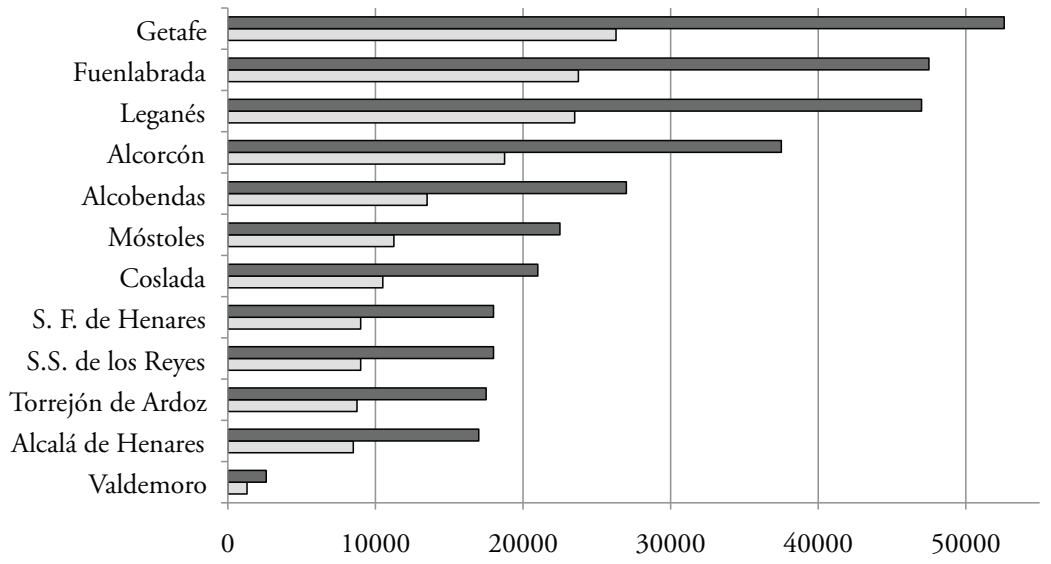

$\square$ Trabajadores que proceden de o trabajan en otros municipios de su zona estadística

$\square$ Trabajadores que proceden de otro municipio de su zona estadística

fuente Atlas de Movilidad Residencia-Trabajo de la Comunidad de Madrid (2010) y elaboración propia.

Por tanto, si los subcentros del norte y del oeste metropolitano se caracterizan por ser los principales focos de atracción de trabajadores procedentes de la capital (además de presentar una notable dependencia de esta última), destacando las localidades de Alcobendas y Pozuelo de Alarcón (ambas conectadas a la red de Metro mediante la ampliación de la línea 10 y del Metro Ligero Oeste, respectivamente), los subcentros del sur metropolitano no solo presentan el mayor número de trabajadores residentes que deben desplazarse a diario a la ciudad central, sino también los mayores flujos transversales de movilidad laboral entre ellos. En este contexto, en abril de 2003 el gobierno de la Comunidad de Madrid inauguró una nueva línea de Metro -denominada MetroSur- no solo para mejorar las comunicaciones transversales entre los grandes subcentros del sur (que sería el objetivo prioritario), sino también para facilitar los desplazamientos radiales entre estas localidades y la capital. ${ }^{4}$

4 Además de conectar con la red principal de Metro con la estación de Puerta del Sur (línea 10), MetroSur facilita el acceso a las líneas de tren C3 (por medio de la estación de El Casar), C4 (por Getafe Central) y C5 (por medio de las estaciones de Fuenlabrada Central, Leganés Central, Móstoles Central y Alcorcón Central), que enlazan los subcentros del sur con la ciudad de Madrid. 


\section{El transporte público en la región metropolitana de Madrid}

La inversión en transporte público se justifica por su mayor eficiencia y por la necesidad de reducir las externalidades negativas en forma de congestión y contaminación debidas a un uso excesivo del automóvil privado. Mella y López (2006) muestran que las ciudades compactas permiten una mayor eficiencia en el transporte colectivo, a pie y en bicicleta, mientras que en las ciudades dispersas suele producirse una mayor dependencia del transporte privado, lo que origina mayores congestiones. Por otro lado, un estudio de la Asociación Internacional del Transporte Público (UITP, 2005) demuestra que, por término medio, el transporte público resulta más eficaz que el automóvil en las zonas densamente pobladas, ya que consume hasta 2,2 veces menos energía por viajero-kilómetro transportado que el vehículo privado, y cuesta 1,6 veces menos. Además, la eficiencia energética del transporte varía según modos. Así, el consumo energético en autobús o ferrocarril es de 3 a 5 veces menor que el del coche o avión por pasajero-kilómetro en plena carga. De los medios motorizados, el Metro es el modo de transporte más eficiente en términos de consumo energético, seguido de cerca por el Metro Ligero.

La estructura territorial de la RMM, que presenta una configuración híbrida y cambiante en el tiempo, necesita de una combinación de transporte privado y público, junto a una estrategia de planificación coordinada entre los diferentes responsables de la movilidad. En Madrid esta coordinación corresponde al Consorcio Regional de Transportes (CRTM), creado en 1986 con el objeto de aglutinar los esfuerzos relacionados con el transporte público de instituciones públicas y privadas. Este marco institucional ha promovido un importante desarrollo de infraestructuras de transporte que, tras el período de atonía de los años ochenta, surgió con fuerzas renovadas a mediados de los noventa.

La mejora del transporte privado se ha basado en una extensión significativa de la red de autopistas. Esta mejora se ha combinado con un decidido esfuerzo de ampliación y mejora del transporte público. Así, los datos de la EMTA (European Metropolitan Transport Authorities) de 2009 muestran que el uso del transporte público en Madrid es bastante elevado. En la Almendra Central se sitúa en el $40,1 \%$, por encima de otras ciudades con densidades similares, como París (34\%) y Berlín (21\%). En la zona metropolitana, la utilización del transporte público también es bastante superior en Madrid (31,6\%) que en esas capitales (20,5\% y 16\%, respectivamente). Por otro lado, a pesar del crecimiento de la población y de los desplazamientos en la zona periférica, donde es más eficiente el uso del transporte privado por su menor densidad de población, no se ha reducido el uso del transporte público global: la Encuesta de Movilidad de 2004 mantiene unos porcentajes entre ambos usos similares a los de la encuesta de 1996 (53\% de uso del transporte público). Las causas del mantenimiento del uso del transporte público a pesar de la mayor dispersión de la ciudad están en la inversión en infraestructuras, que ha reducido los tiempos de viaje y mejorado la calidad del servicio.

No obstante, es importante diferenciar entre distintas zonas metropolitanas y distintos modos de transporte. En la Almendra Central, con una alta densidad de población e importantes dificultades para utilizar el vehículo privado, el transporte público presenta 
una gran ventaja respecto del privado. En esta zona las autoridades han apostado por potenciar el transporte público con el desarrollo del Metro y los autobuses urbanos, a la vez que han encarecido el uso del coche privado mediante el establecimiento de un Sistema de Estacionamiento Regulado. En la Periferia Urbana, dentro todavía de la ciudad, se ha ampliado igualmente la red de Metro y los autobuses urbanos, además de crearse un sistema de intercambiadores entre modos de transporte para reducir los tiempos de transbordo.

Los movimientos de entrada y de salida desde la ciudad hacia los municipios de la Corona Metropolitana también se han visto reforzados con el transporte público, tanto de autobuses interurbanos -operados por compañías privadas reguladas por las autoridades (CRTM) mediante un sistema de concesión por zonas- como de trenes de Cercanías que aprovechan el trazado de larga distancia entre Madrid y el resto de España para atender los desplazamientos urbanos. La competitividad de estas infraestructuras radiales se basa en la existencia de municipios densamente poblados (apartado 1) para rentabilizar los desplazamientos desde y hacia la capital. Sin embargo, los movimientos transversales entre los municipios de la Corona Metropolitana son más complejos de cubrir por el transporte público.

En este sentido, el principal esfuerzo de inversión en transporte público se ha centrado en la ampliación de la red de Metro. Hasta 1995 su longitud era de 114 kilómetros, y desde entonces ha duplicado con creces su tamaño mediante planes de inversiones cuatrienales, hasta alcanzar los 295 kilómetros en 2011. El hecho de que el Metro de Madrid sea el séptimo mayor del mundo, mientras que la metrópoli es solo la decimoséptima por tamaño de población y por número de pasajeros transportados anualmente, muestra cómo los gobiernos madrileños han dado prioridad al Metro frente a otros medios de transporte público. Así, el Cuadro 1 refleja cómo el Metro ha pasado a ser el principal modo de transporte público en Madrid, representando más de $40 \%$ de la demanda total del mismo, y en la última década ha incrementado su importancia relativa frente al ligero descenso de los otros modos.

CUADRO 1 | Reparto modal del transporte público de Madrid (2001-2011) (porcentajes)

\begin{tabular}{|c|c|c|c|c|c|}
\hline AÑo & METRO & $\begin{array}{c}\text { METRO } \\
\text { Ligero }\end{array}$ & $\begin{array}{c}\text { AUTOBUSES } \\
\text { URBANOS }\end{array}$ & $\begin{array}{c}\text { AUTOBUSES } \\
\text { INTERURBANOS }\end{array}$ & $\begin{array}{c}\text { TREN DE } \\
\text { CERCANÍAS }\end{array}$ \\
\hline 2000 & 36,1 & - & 34,1 & 15,4 & 11,1 \\
\hline 2001 & 36,2 & - & 33,2 & 15,8 & 11,8 \\
\hline 2002 & 37,3 & - & 31,6 & 14,9 & 13,1 \\
\hline 2003 & 39,1 & - & 30,7 & 14,9 & 12,5 \\
\hline 2004 & 39,5 & - & 30,5 & 14,7 & 12,5 \\
\hline 2005 & 40,6 & - & 29,7 & 14,4 & 12,5 \\
\hline 2006 & 40,7 & - & 29,9 & 13,9 & 12,6 \\
\hline 2007 & 42,5 & 0,3 & 28,2 & 13,7 & 12,3 \\
\hline 2008 & 43,2 & 0,9 & 26,9 & 13,6 & 12,4 \\
\hline 2009 & 42,8 & 1,1 & 28,1 & 13,0 & 12,0 \\
\hline 2010 & 42,5 & 1,2 & 28,7 & 12,4 & 12,2 \\
\hline 2011 & 42,6 & 1,2 & 28,7 & 12,4 & 12,1 \\
\hline
\end{tabular}

FUENTE CRTM (2011) Y ELABORACIÓN PROPIA. 


\section{La expansión del transporte público ferroviario hacia la Corona Metropolitana}

(1999-2011)

El crecimiento de la ciudad de Madrid, su expansión hacia los municipios de la Corona Metropolitana y el consiguiente incremento de la complejidad en la movilidad de la RMM, han llevado a los gobiernos madrileños a desarrollar, desde 1999, nuevas infraestructuras ferroviarias en los municipios que rodean la capital. A continuación se detallan las sucesivas ampliaciones de la red de Metro, teniendo en cuenta la Figura 3 y los datos del Cuadro A1.

La primera ampliación de Metro se dirigió hacia dos municipios del sudeste metropolitano, Rivas-Vaciamadrid y Arganda del Rey. La zona sudeste es la menos poblada de la región, y a lo largo de la autovía A-3 que configura este corredor no existen subcentros que hagan pensar que esta zona se convierta a corto plazo en un polo relevante de atracción de habitantes y trabajadores. A pesar de ello, la elección de esta zona para ejecutar la primera ampliación de la red de Metro fuera de los límites de la ciudad de Madrid respondió, en primer lugar, al rápido y extraordinario crecimiento de su población y del empleo. El aumento de la población ha sido el mayor de la región, destacando las localidades de Rivas-Vaciamadrid (con un incremento del 126\% entre 2001 y 2011) y Arganda del Rey (cuya elevación ha sido del 68,6\%). El crecimiento del empleo también ha sido muy alto -143,94\% en el municipio de Rivas-Vaciamadrid-, solo superado por alguna localidad del norte y del oeste metropolitanos. Además, debe añadirse que en esta zona no existían trenes de Cercanías y que está prevista la construcción de un aeropuerto en el municipio de Campo Real, situado en la prolongación de este corredor metropolitano. La ampliación hacia los municipios del sudeste ha consistido en unir la línea 9 de Metro a una línea ferroviaria denominada TFM (Transportes Ferroviarios de Madrid) que conecta con las dos poblaciones anteriormente mencionadas. La nueva línea posee unas características mucho más parecidas al tren, ya que la distancia entre sus estaciones es mayor, los trenes tienen una menor frecuencia, y pueden alcanzar mayores velocidades (hasta $110 \mathrm{~km} / \mathrm{hora}$ ).

El sur metropolitano se puede considerar como una ciudad en sí misma, ya que como pudo comprobarse en el primer apartado- concentra más de 1.280.000 habitantes. La crisis industrial que sufrió la RMM en la década de los ochenta supuso una violenta destrucción de empleo en las poblaciones industriales de esta zona de la Corona Metropolitana. Estas localidades presentan altas concentraciones de población, pero con ratios empleo/trabajadores residentes inferiores a la unidad (excepto el municipio de Getafe), lo que implica que gran parte de sus trabajadores residentes debe desplazarse a diario hacia la capital o hacia otros municipios del mismo sur metropolitano. Por otro lado, cada uno de estos municipios cuenta con importantes centros generadores de desplazamientos nolaborales como hospitales, ${ }^{5}$ universidades, ${ }^{6}$ y centros comerciales y de ocio.

5 Seis repartidos entre los principales núcleos urbanos: Getafe, Fuenlabrada, Alcorcón, Leganés, y dos en Móstoles.

6 Tres de los cuatro campus de la Universidad Rey Juan Carlos (con 32.858 alumnos) se hallan en los municipios de Móstoles, Fuenlabrada y Alcorcón, mientras que la Universidad Carlos III (con 18.419 alumnos) cuenta con sedes en las localidades de Getafe y Leganés. 
FIgURA 3 | Red de Metro de Madrid en 2011

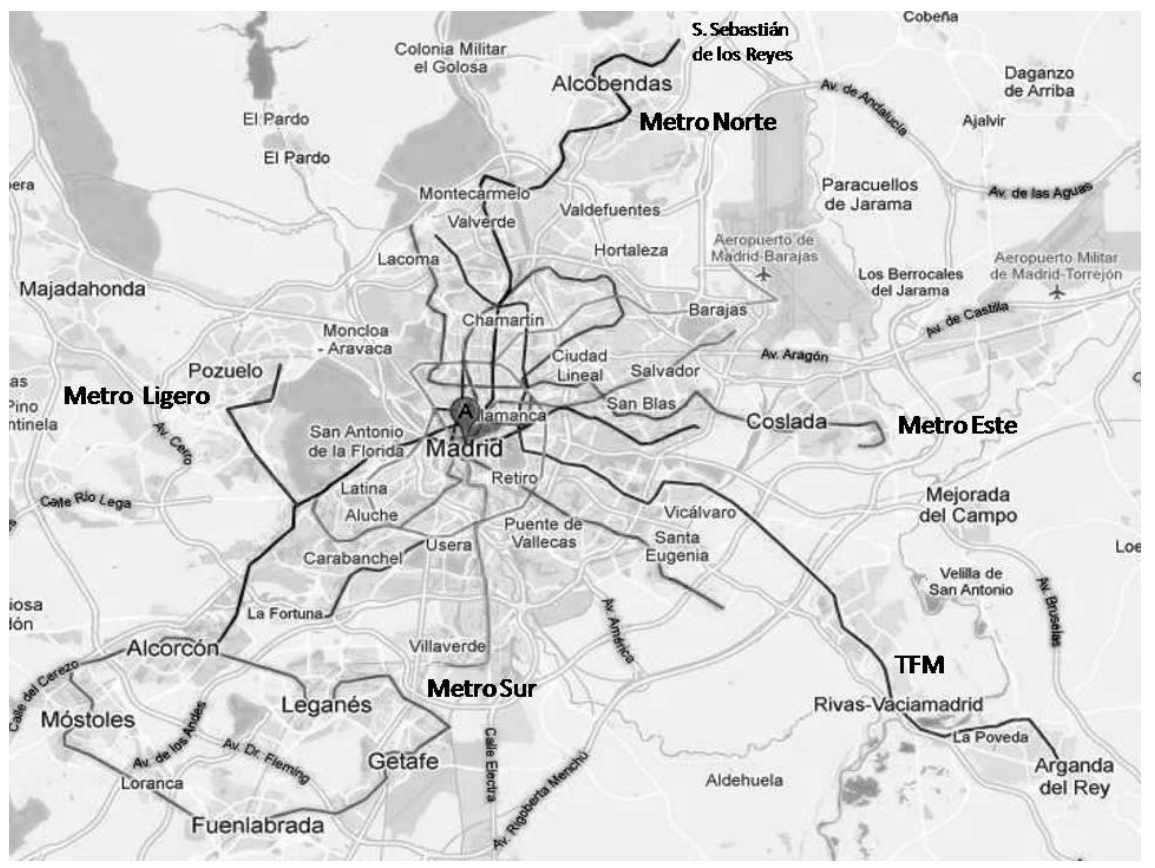

FUENTE Google Maps y elaboración PRopia.

Aunque el sur está bien comunicado con la capital (dispone de tres autopistas radiales y numerosos trenes de Cercanías y autobuses interurbanos), la importancia de esta zona llevó al gobierno de Madrid a realizar la segunda ampliación de la red ferroviaria en el año 2003 con la creación de MetroSur, una línea circular que conecta los cinco subcentros del sur metropolitano (Figura 3). En la práctica, se trata de una línea relativamente independiente del resto de la red de Metro, ya que solo está unida al suburbano por una estación (Puerta del Sur), si bien están previstas nuevas conexiones en el futuro. El principal objetivo de esta ampliación fue el reforzamiento de los movimientos transversales entre las grandes localidades del sur, más que los desplazamientos radiales con la capital. Parla quedó fuera del trazado de MetroSur debido a su localización geográfica más alejada de los otros cinco municipios, pero su gran densidad de población hizo necesaria la introducción en 2007 de un nuevo sistema de transporte ferroviario: el tranvía de Parla. Su trazado es circular dentro del municipio, por lo que se aproxima más a la idea del tranvía tradicional frente a las otras líneas de Metro Ligero que se inauguraron en 2007, con una vocación más radial.

En 2007 también se amplió el Metro hacia el este y el norte metropolitanos de forma similar al TFM antes descrito. MetroEste es una prolongación de la línea 7 de Metro hacia las poblaciones de Coslada (uno de los trece subcentros de la RMM) y San Fernando de Henares, cuyas características socioeconómicas son parecidas a las 
de las poblaciones del sur. MetroNorte implica la misma solución con la ampliación de la línea 10 de Metro hacia los subcentros de Alcobendas y San Sebastián de los Reyes, aunque -como puede comprobarse en el Cuadro A1- las características de estas poblaciones son muy diferentes a las del sur y el este de la región. Efectivamente, la zona norte está atrayendo en los últimos años a numerosas empresas y oficinas, principalmente del sector servicios, que tradicionalmente se habían concentrado en la ciudad central. Esto se refleja en ratios empleo/trabajadores residentes de sus subcentros superiores a la unidad, lo que los convierte en núcleos de atracción de trabajadores procedentes de otras zonas de la RMM, especialmente de la capital. De igual modo, han proliferado numerosos centros comerciales y de ocio, mientras que el transporte público era bastante deficiente. Si a esto se une la cantidad de población residencial que ha atraído (276.000 habitantes) y su alta densidad, es justificable la rentabilidad de la ampliación de la red de Metro hacia esta zona de la Corona Metropolitana.

La zona oeste es la que más dinamismo ha mostrado para atraer población, habiendo absorbido desde 2001 más de 75.000 nuevos habitantes y creado nuevos empleos. Los municipios agrupados alrededor de la autopista A-6 se han convertido en una de las zonas residenciales más atractivas de Madrid, tal y como muestra su reducida densidad de población, sus viviendas unifamiliares y su elevada renta media. En esta zona se desarrolló en 2007 otra de las novedades de ampliación del transporte ferroviario madrileño, el Metro Ligero. Las dos líneas situadas en la zona Noroeste: ML-2 (Pozuelo de Alarcón) y ML-3 (Boadilla del Monte), denominadas Metro Ligero Oeste, suponen una ampliación hacia esta zona similar a otras prolongaciones radiales del metro convencional (MetroNorte, MetroEste y TFM), aunque se diferencian de estas últimas en que su red de plataformas no se configura tanto como un sistema de penetración directa al centro, sino como un sistema de ámbito metropolitano de apoyo a los modos de transporte colectivo de la zona. ${ }^{7}$ Metro Ligero Oeste presenta las características propias de este transporte: menor velocidad, gran número de estaciones, trazado en superficie y facilidad en el acceso. Su elección, en vez del metro convencional, responde a la reducida densidad de población de las localidades del oeste metropolitano, y a la dispersión de buena parte de sus habitantes y de sus centros de ocio y de trabajo.

Bajo la denominación de Metro Ligero también se incluyen otros modos ferroviarios, como el Tranvía de Parla, comentado previamente, o la línea ML-1. Estos modos están operados por cuatro empresas privadas (TFM, Metro Ligero Oeste, Metros Ligeros de Madrid y Tranvía de Parla) -denominadas "concesiones ferroviarias"- que explotan la red bajo el régimen de concesión y son independientes de Metro de Madrid. La línea ML-1 está ubicada en la ciudad de Madrid para dar servicio a nuevos desarrollos urbanísticos en la zona (Las Tablas y Sanchinarro). En realidad, esta ampliación de la red de Metro sirve de conexión a otras líneas ya

$\mathrm{Al}$ igual que MetroSur, Metro Ligero Oeste es una línea relativamente independiente del resto de la red de Metro (con una única conexión en la estación de Colonia Jardín), y solo dispone de correspondencia con una línea de Cercanías (Aravaca), aunque están previstas más conexiones y la creación de intercambiadores de autobuses y trenes. 
existentes (L-1, L-4 y L-10), buena parte de su trazado es subterráneo (70\%), y su velocidad es mayor y cercana a la del metro convencional.

Por último, el corredor M-607, que incluye los municipios de Tres Cantos y Colmenar, reúne las características de concentración de empleo (en el caso de Tres Cantos), acumulación de centros de ocio y comerciales, y atracción residencial (renta elevada, juventud de la población...). Sin embargo, su menor población y su mayor distancia a la capital han hecho que todavía no se hayan desarrollado ampliaciones en sus infraestructuras ferroviarias, excepto el tren de Cercanías.

\section{Análisis de los diferentes modos ferroviarios en la ampliación del transporte público madrileño}

A partir de 1999 se han desarrollado diferentes opciones de transporte ferroviario en los municipios de la Corona Metropolitana. Además de la red de Cercanías existente, las otras opciones han sido la ampliación radial de líneas de Metro con características cercanas al tren (TFM, MetroEste y MetroNorte), una línea de Metro circular que conecta varios municipios del sur metropolitano (MetroSur), el Metro Ligero como forma de conexión entre líneas de Metro ya existentes (ML-1), el Metro Ligero de ampliación hacia zonas periféricas (Metro Ligero Oeste), y el tranvía (Parla). En este apartado se estudian las ventajas y desventajas de las diferentes opciones como paso previo para analizar su eficiencia.

Los modos que presentan mayor ventaja en términos de velocidad y capacidad de transporte de viajeros son, por orden, el tren, el metro, el metro ligero y el tranvía, pero el orden es el inverso cuando la ventaja se refiere a la comodidad de acceso, al número de estaciones y a la flexibilidad en el trazado. En todos los casos, salvo el del tranvía, se trata de infraestructuras cuya plataforma es independiente respecto de la circulación rodada, lo que permite evitar las congestiones de hora punta y otorga una ventaja competitiva frente a los autobuses urbanos e interurbanos que comparten la circulación con los vehículos privados. Otra diferencia reside en que el metro es subterráneo, por lo que no genera externalidades negativas de ruido o división del entorno urbano.

Como ejemplo de transporte suburbano en Madrid están las ampliaciones radiales (TFM, MetroEste y MetroNorte) y MetroSur. Por otro lado, la línea ML-1 es un modo de transporte híbrido entre el metro ligero y el metro convencional. Finalmente, como línea pura de metro ligero está el Metro Ligero Oeste, cuyas líneas (ML-2 y ML-3) constituyen una prolongación de la red de Metro hacia las localidades del oeste que no disponían de este servicio. Ambas líneas presentan un trazado más urbano que trata de conectar entre sí los diferentes núcleos urbanísticos, empresariales y de servicios ubicados en esta demarcación de la RMM. Por otro lado, las dos líneas circulan en su mayor parte en superficie, lo que las dota de otras ventajas: son más flexibles en su trazado, ya que este puede modificarse una vez puestas en funcionamiento, permitiendo incorporar o eli-

minar estaciones y crear paradas de carácter discrecional; y son más accesibles, 
ya que disminuyen la incomodidad y el coste de acceso a la estación subterránea del metro o a los andenes del tren.

La infraestructura de Metro Ligero es uno de sus elementos más destacados y diferenciadores en comparación con el resto del transporte urbano de Madrid. Los sistemas de Metro Ligero, al igual que el tren de Cercanías, se caracterizan por discurrir en superficie en la mayor parte de su recorrido. Sin embargo, a diferencia de los antiguos tranvías, y al igual que ocurre con el Metro, la plataforma es independiente respecto de la circulación rodada, lo que permite reducir los tiempos de viaje, especialmente en hora punta. En este sentido, Metro Ligero comparte con Cercanías y Metro el poder evitar estas congestiones, lo que les confiere una ventaja competitiva frente a los autobuses urbanos e interurbanos, donde incluso la posibilidad de establecer plataformas segregadas - con los carriles bus- no logra evitar del todo los problemas de congestión. No obstante, esa independencia genera otros problemas, fundamentalmente los efectos negativos provocados en el entorno urbano por el hecho de circular en superficie. Las vías por las que discurre el Cercanías suponen una división en el entorno urbano, al representar un obstáculo importante para el movimiento de personas y el resto de vehículos que quieran atravesar las vías del ferrocarril. La construcción de túneles o plataformas elevadas para el tren apenas puede superar estos problemas, ya que construir túneles para los trenes de Cercanías es muy costoso y no se contempla como una opción eficiente y viable, salvo para superar determinados obstáculos muy concretos. El Metro no tiene este problema al transcurrir por el subterráneo de la ciudad, y el Metro Ligero, aunque discurre en la mayor parte de su trazado en superficie, posee unas características técnicas que limitan las interferencias con la movilidad de los peatones y el resto de vehículos, e incluso permiten obtener ventajas adicionales derivadas de su implantación.

Efectivamente, en primer lugar, la infraestructura del Metro Ligero implica construir, en la plataforma de circulación, un conjunto de sistemas específicos de señalización y regulación del tráfico. Estos sistemas interactúan con la regulación semafórica del tráfico viario de la ciudad, permitiendo dar prioridad al Metro Ligero, a la vez que minimizan su repercusión en el tráfico urbano de peatones y vehículos. En segundo lugar, el Metro Ligero permite mejorar la urbanización integral de las zonas por las que discurre y potenciar nuevas zonas urbanizadas, mediante la reserva de superficie pública consolidada y la posibilidad de peatonalizar algunas zonas urbanas, como ha ocurrido con algunos tramos del Metro Ligero ${ }^{8}$ y el Tranvía de Parla. ${ }^{9}$ Finalmente, la circulación en superficie del Metro Ligero permite una gran flexibilidad en su trazado y en las paradas que efectúa. Un ejemplo de esta flexibilidad se ha podido comprobar en el proceso de construcción de la línea

8 Por ejemplo, en el caso de Boadilla se ha puesto mucho énfasis en el acondicionamiento y ajardinamiento de las zonas que flanquean el trazado de la línea ML-3 a su paso por esta población.

9 Esta población está teniendo un gran desarrollo urbano e industrial que está modificando profundamente su configuración. En este sentido, el tranvía pretende integrar estos nuevos desarrollos urbanos, las nuevas infraestructuras y las zonas más consolidadas de la ciudad. Además, aspira a actuar como elemento dinamizador de los accesos a la propia ciudad al enlazar la red de autobuses urbana e interurbana con la red de Cercanías. Finalmente, la introducción de esta infraestructura ha estado acompañada de la peatonalización de algunas zonas céntricas. 
ML -2, donde las presiones vecinales consiguieron modificar su trazado original. El cambio de este trazado se puede realizar incluso una vez construido, pudiéndose añadir o eliminar paradas sin un gran coste.

La mayor flexibilidad del Metro Ligero también se materializa en un mayor número de paradas (Cuadro 2), por requerirse una menor distancia entre ellas. Como resultado, mejora la accesibilidad al reducirse las distancias y tiempos de acceso y dispersión, con lo que las estaciones adquieren una entidad más afín a las paradas de autobús que a las estaciones de Metro (si bien hay que tener en cuenta que cuantas más paradas se diseñen, mayor será el tiempo de duración del viaje). Además, las paradas pueden funcionar con carácter discrecional, evitándose la detención cuando no hay viajeros que deseen bajar o subir; de este modo, pueden cubrirse aquellos puntos que cuentan con una demanda estacional, debido a la reducida inversión para la construcción de la estación y la ausencia de condicionantes que impone la explotación habitual de la línea. Curiosamente, el Cuadro 2 muestra cómo la distancia media entre las estaciones del Metro Ligero (772 metros) no es excesivamente inferior a la del metro convencional (1.021 metros), y similar a la que existía antes de las ampliaciones comenzadas en 1995 (736 metros). ${ }^{10}$ Esto indica que inicialmente se ha optado por no establecer demasiadas paradas en estas primeras líneas de Metro Ligero, aunque la flexibilidad de este modo de transporte permitirá añadir nuevas paradas intermedias en el futuro.

CUADRO 2 Comparación de la distancia media entre estaciones en el tren de Cercanías, el metro convencional y el Metro Ligero

\begin{tabular}{|l|r|r|c|}
\hline & $\begin{array}{c}\text { LONGITUD } \\
(\text { KM })\end{array}$ & $\begin{array}{c}\text { NÚMERO DE } \\
\text { ESTACIONES }\end{array}$ & $\begin{array}{c}\text { KM ENTRE } \\
\text { ESTACIONES }\end{array}$ \\
\hline TREN CERCANÍAS & 387 & 100 & 3,905 \\
\hline Tren Móstoles-Navalcarnero (proyecto) & 15 & 7 & 2,500 \\
\hline METRO CONVENCIONAL & 260 & 279 & 0,937 \\
\hline CONCESIONES FERROVIARIAS (sin Metro Ligero) & 28 & 22 & 1,343 \\
\hline Metro hasta 1995 & 120 & 164 & 0,736 \\
\hline Ampliación 1995-1999 & 56 & 38 & 1,514 \\
\hline Ampliación 1999-2003 (sin Metro Sur) & 8 & 6 & 1,644 \\
\hline Metro Sur & 41 & 28 & 1,500 \\
\hline Ampliación 2003-2007 (sin Metro Este y Norte) & 28 & 23 & 1,283 \\
\hline Metro Este & 9 & 8 & 1,334 \\
\hline Metro Norte & 16 & 11 & 1,557 \\
\hline METRO LIGERO & 28 & 37 & 0,772 \\
\hline ML-1 & 5 & 9 & 0,675 \\
\hline ML-2 & 9 & 13 & 0,725 \\
\hline ML-3 & 14 & 16 & 0,913 \\
\hline Tranvía de Parla & 8 & 15 & 0,586 \\
\hline
\end{tabular}

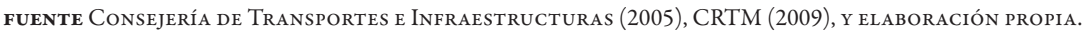

10 Hasta ese año, el Metro se situaba en el centro de Madrid con un trazado mucho más tupido, mientras que las recientes ampliaciones hacia la Periferia Urbana y la Corona Metropolitana han incrementado las distancias entre estaciones. 
Una de las características más destacadas de las estaciones del Metro Ligero es su mayor accesibilidad, superior a la del metro convencional, a la del Cercanías (donde suelen ser necesarias las escaleras cuando el tren no para en la vía principal de la estación, y además el piso de los vagones no está al nivel del suelo) y a la de los autobuses (en los que el piso tampoco está al nivel del suelo y necesitan sistemas especiales de rampa para los discapacitados). El carácter superficial del Metro Ligero evita los problemas de acceso a las estaciones subterráneas y a las secciones del andén. Además, al disponer de vehículos de piso bajo (35 centímetros sobre el plano de rodadura) se han construido miniandenes que, por su reducida altura, se integran perfectamente con las aceras existentes, favoreciendo el acceso de personas con movilidad reducida a través por un sistema de suaves rampas.

Junto a los factores de producción convencionales anteriores, el tiempo es otro factor utilizado para la producción de servicios de transporte. Sin embargo, a diferencia de los otros, este factor no es aportado por las empresas de transporte sino por los propios usuarios: los viajeros invierten un recurso escaso y no transferible, su propio tiempo, que gastan sin posibilidad de utilización alternativa. Aunque en otras empresas productoras de bienes y servicios de consumo los usuarios finales también participan aportando cierta cantidad de tiempo en las actividades de consumo necesarias para extraer la utilidad de los bienes (por ejemplo, en la restauración o el ocio), en el transporte el tiempo se convierte en una variable tan importante o más que el coste monetario del servicio para los consumidores. Salvo en los viajes turísticos, el tiempo empleado en el transporte es un bien de consumo intermedio, es decir, se utiliza para llevar a cabo otras actividades (trabajo, estudios, ocio...), por lo que el usuario desea minimizarlo al ser fuente de desutilidad.

La empresa suministradora de transporte puede modificar el tiempo consumido por los usuarios mediante cambios en el resto de los factores de producción. Así, puede tomar decisiones sobre la velocidad del vehículo, su frecuencia de paso o su capacidad. En el caso concreto del Metro Ligero, existen diferentes opciones para reducir el tiempo invertido en el transporte. Ejemplos de estas opciones son la decisión de soterrar la línea ML-1 para aumentar su velocidad o la de apostar por un trazado más urbano en la ML-3, fijar un mayor o menor número de estaciones en función de la rapidez que se quiera conseguir y de la integración del trazado en el recorrido urbano, o establecer la composición modular de los vehículos para adaptarlos a las necesidades de cada línea y de cada tramo horario.

En un sistema de transporte, el análisis del tiempo debe centrarse en la duración total del viaje desde el lugar de salida al de destino (la denominada "puerta a puerta”). En este sentido, el Metro Ligero, al ser capaz de unir determinadas poblaciones con otros sistemas de transportes como el Metro y Cercanías, permite reducir el tiempo total de viaje. Además, la elección entre transporte público y privado muchas veces depende de la existencia de servicios públicos que enlacen el origen y el destino del viaje, conexiones que el Metro Ligero ayuda a realizar. Por otro lado, 
existe la posibilidad de adaptar el Metro Ligero para que pueda utilizar las vías del tren de Cercanías o del Metro. ${ }^{11}$

Otro elemento que distingue los diferentes tipos de transporte ferroviario es su coste de inversión y su financiación. El Cuadro 3 compara el coste de construcción del Metro Ligero con el del metro convencional en función de sus tres elementos principales: las cocheras, el equipo móvil y la infraestructura. Según estos datos, es cuatro veces más barato construir un kilómetro de Metro Ligero que uno de metro convencional: el coste de las cocheras en el Metro Ligero es $40 \%$ del coste en el metro convencional, el del material móvil 30\% (ya que pesa menos que el del metro convencional, lo que le permite tener mejores prestaciones de aceleración), y el de las infraestructuras el 25\% (aunque este puede aumentar considerablemente si la infraestructura va soterrada, como ocurre en el caso de la línea ML-1, con un coste de 44 millones de euros por cada kilómetro construido, frente a los 13 millones en el caso del Metro Ligero). Ponderando en función del peso de cada elemento en el presupuesto total, 10\%, 20\% y 70\%, respectivamente, según la Consejería de Transportes e Infraestructuras (2005), el coste del Metro Ligero supone 27,5\% del coste del metro convencional (Gallego \& Pires, 2008).

Para financiar los costes de inversión y explotación (costes de personal, energía, adquisición de bienes y servicios, conservación...) de los sistemas de transporte ferroviario, las compañías disponen de los ingresos tarifarios y de los procedentes de la publicidad. El Metro Ligero está plenamente integrado en el sistema comercial y tarifario del CRTM. Este establece diferentes tarifas en función de la división territorial en coronas o zonas tarifarias, más caras cuanto más alejadas estén del centro. El precio del billete viene definido por la corona en la que se utiliza, o por las zonas que se atraviesan en el desplazamiento. Todas las líneas de Metro Ligero (ML-2 y ML-3, además del Tranvía de Parla) tienen las mismas tarifas que el resto de zonas de la red de Metro (incluyendo la ML-1, MetroNorte, MetroEste, TFM y MetroSur). Las tarifas de abono permiten utilizar todas las redes indistintamente, siempre en función de la zona.

Los precios están fijados por la Administración, lo que provoca que en la mayor parte de los servicios no se pueda conseguir el equilibrio financiero de la explotación. Esto obliga a la Administración a restablecer el citado equilibrio mediante subvenciones o compensaciones de servicio público. El Consorcio Regional de Transportes establece por ley este principio de tarifa de equilibrio o tarifas suficientes. Con ello se pretende que las empresas públicas que prestan los servicios de transporte cubran la totalidad de los costes reales en condiciones normales de productividad y organización. La compensación está vinculada directamente al servicio

11 Por ejemplo, en la ciudad alemana de Karlsruhe (cuna del "tren-tram") los vehículos tranviarios son muy largos y suelen circular en doble composición formando trenes bastante grandes. Parte de un mismo recorrido puede desarrollarse por una calle peatonal a poca velocidad, otra parte por calles con plataforma reservada y prioridad semafórica, y una última por vías ferroviarias convencionales mezclándose con el resto de tráficos ferroviarios, a velocidades bastante elevadas y distancias muy grandes. Aunque estas posibilidades aún no se han contemplado en el caso de Madrid se podrían introducir en el futuro, siendo una opción más dentro de la flexibilidad que el Metro Ligero introduce en la red de transporte público de Madrid. 


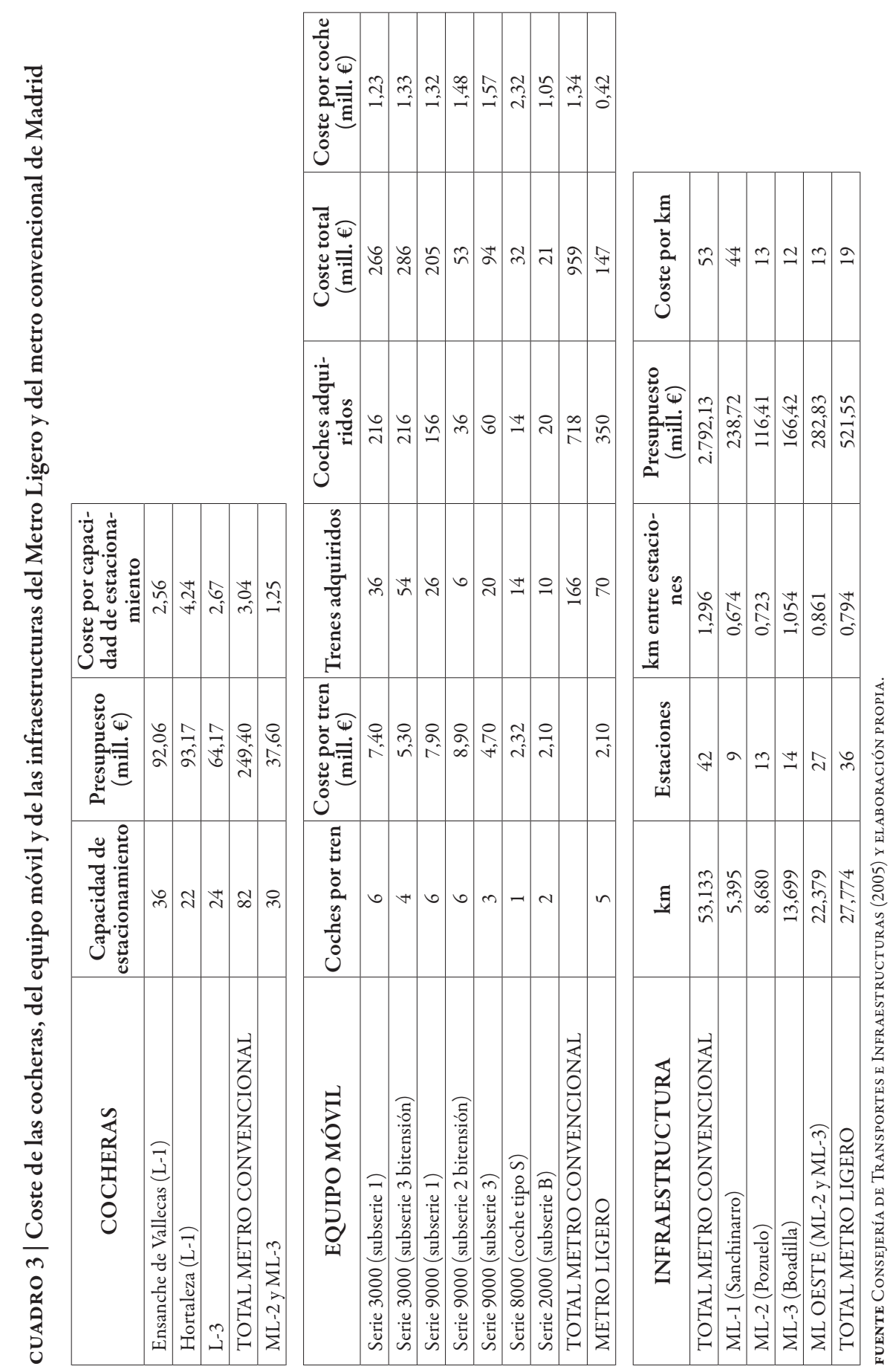


prestado. Cuando las tarifas a cargo del usuario son inferiores a la de equilibrio, la diferencia se completa mediante el abono por parte del CRTM de una compensación económica a las correspondientes empresas.

Respecto de la financiación del Metro Ligero, deben destacarse dos ideas. La primera es que, desde el punto de vista de la Administración, el objetivo de subvencionar el transporte público para reducir las externalidades negativas vinculadas al uso del transporte privado también debe tener en cuenta la finalidad de aprovechar al máximo las posibilidades que existen de optimizar la gestión mediante una adecuada integración del conjunto del sistema de transportes. Los objetivos deben ser incrementar los ingresos (mediante una modulación del sistema tarifario), luchar contra el fraude, aumentar la productividad, mejorar la gestión de las empresas y potenciar la iniciativa privada tanto en la gestión como en la financiación. La segunda idea tiene que ver con la perspectiva del usuario, ya que el coste del billete no es la variable decisiva para determinar la demanda de esta modalidad de transporte, sino otras variables, como el tiempo de viaje, la conexión a otros modos, la puntualidad o la comodidad.

Por último, se analiza la eficiencia de las ampliaciones de la red de Metro -ya sea metro ligero o metro convencional- hacia la Corona Metropolitana. Una primera aproximación consiste en estudiar la demanda y el uso de las nuevas infraestructuras, en comparación con el resto del transporte público madrileño. El Cuadro 4 compara el incremento de la demanda de viajeros de las nuevas ampliaciones con el de la demanda de la red global de Metro. La entrada en funcionamiento de una nueva línea de Metro siempre genera un incremento de la demanda, al empezar a utilizarla viajeros procedentes de otros medios de transporte público y privado. Esto es lo que ha ocurrido en todas las nuevas líneas introducidas desde 1999, con un incremento superior al de la media durante sus primeros años de existencia. No obstante, a medida que pasan los años, la demanda de esas líneas se estabiliza y su crecimiento se torna similar al de la red global de Metro. Es más, las dos líneas de las que existen datos para varios años (TFM y MetroSur) están teniendo un comportamiento peor que el resto de la red. La evolución de una línea en particular depende de varios factores, además de su propia calidad, como la entrada en servicio o la mejora de otros modos de transporte público o infraestructuras privadas, por lo que sería necesario realizar estudios individualizados de cada línea, algo que supera las pretensiones de este artículo. El Cuadro 4 también refleja cómo la crisis económica iniciada en 2008 ha reducido la movilidad general, observándose un descenso del número total de viajeros que utilizan el transporte público, incluido el Metro de Madrid. No obstante, en este último caso, a pesar de la reducción de la demanda de viajeros en los años 2009 (5,7\%) y 2010 (2,3\%), en 2011 ha vuelto a repuntar (aumentando 1,21\%). Por otro lado, el Metro sigue siendo el medio de transporte público más utilizado, no observándose una reducción de su peso relativo respecto de otros modos de transporte público. Las nuevas líneas creadas en 2007 presentan una evaluación más favorable, con un gran incremento en el segundo año de actividad (2007-2008) y un crecimiento mayor que la media de la red de Metro en 
los dos años siguientes. La única línea con un menor crecimiento en sus primeros años de creación, aunque siempre por encima de la media de la red de Metro, es la ML-3 (Boadilla). El cuadro también refleja cómo el crecimiento de la demanda en todas estas líneas se ha ido diluyendo con el paso del tiempo (tras el incremento de los primeros años), hasta acabar mostrando un comportamiento muy similar al del conjunto de la red, tal y como sucedió previamente con TFM y MetroSur.

CUADRO 4 | Incremento de la demanda de viajeros en las distintas líneas de metro en Madrid (porcentajes)

\begin{tabular}{|c|c|c|c|c|c|c|c|c|c|c|c|}
\hline $\begin{array}{c}\text { INCREMENTO } \\
\text { ANUAL }\end{array}$ & $\begin{array}{c}\text { TOTAL } \\
\text { METRO DE } \\
\text { MADRID }\end{array}$ & TFM & $\mid \begin{array}{c}\text { Metro } \\
\text { Sur }\end{array}$ & $\begin{array}{c}\text { Metro } \\
\text { Este }\end{array}$ & $\begin{array}{l}\text { Metro } \\
\text { Norte }\end{array}$ & $\begin{array}{c}\text { TOTAL } \\
\text { METRO } \\
\text { PERIFERIA }\end{array}$ & ML-1 & ML-2 & ML-3 & $\begin{array}{c}\text { Tranvía } \\
\text { Parla }\end{array}$ & $\begin{array}{l}\text { TOtAL } \\
\text { METro } \\
\text { Ligero }\end{array}$ \\
\hline $1999-2000$ & 9,4 & 35,6 & - & - & - & 35,6 & - & - & - & - & - \\
\hline $2000-2001$ & 3,6 & 24,9 & - & - & - & 24,9 & - & - & - & - & - \\
\hline $2001-2002$ & 3,9 & 15,3 & - & - & - & 15,3 & - & - & - & - & - \\
\hline $2002-2003$ & 6,5 & $-21,2$ & - & - & - & 388,8 & - & - & - & - & - \\
\hline 2003-2004 & 2,0 & $-5,0$ & 73,1 & - & - & 60,5 & - & - & - & - & - \\
\hline 2004-2005 & 4,4 & 19,2 & 9,9 & - & - & 10,8 & - & - & - & - & - \\
\hline $2005-2006$ & 1,7 & $-2,7$ & 3,6 & - & - & 2,9 & - & - & - & - & - \\
\hline $2006-2007$ & 7,2 & $-4,9$ & 4,2 & - & - & 21,4 & - & - & - & - & - \\
\hline $2007-2008$ & 5,1 & $-3,4$ & 0,2 & 37,7 & 24,2 & 4,4 & 32,4 & 12,6 & $-1,8$ & 29,1 & 17,1 \\
\hline 2008-2009 & $-5,7$ & $-7,6$ & $-9,8$ & 11,4 & 3,9 & $-6,5$ & 17,9 & 12,8 & 2,8 & 11,6 & 11,5 \\
\hline $2009-2010$ & $-2,3$ & $-3,5$ & $-3,0$ & 0,4 & 2,1 & $-2,1$ & 1,4 & $-0,5$ & 1,2 & 14,6 & 4,3 \\
\hline $2010-2011$ & 1,21 & 0,13 & 3,47 & $-0,22$ & 4,76 & 2,89 & $-0,81$ & 0,16 & 0,16 & 3,65 & 0,85 \\
\hline
\end{tabular}

FUENTE CRTM Y ELABORACIÓN PROPIA.

\section{Conclusiones}

En este artículo se ha analizado la adaptación del transporte público al crecimiento de la ciudad de Madrid. El aumento de población y empleo, junto con su desplazamiento desigual hacia la Corona Metropolitana, ha obligado a los gobiernos madrileños a realizar ampliaciones de nuevos modos de transporte. El metro, que constituye el transporte público más utilizado en Madrid, se ha ampliado desde 1999 hacia gran parte de los subcentros de la franja metropolitana a través de diferentes modos: líneas radiales de Metro con características cercanas al tren (TFM, MetroEste y MetroNorte), una línea de Metro circular que conecta varios municipios de la periferia (MetroSur), el Metro Ligero como forma de conexión entre líneas de Metro ya existentes (ML-1), el Metro Ligero de ampliación hacia zonas periféricas del oeste (Metro Ligero Oeste), y el tranvía (Parla).

El estudio de las características socioeconómicas de los corredores metropolitanos hacia donde se han dirigido las nuevas infraestructuras ha permitido analizar las 
causas del desarrollo de estas ampliaciones. En la zona más poblada, el Sur metropolitano, donde ya existían numerosas redes de transporte público, se optó por un metro circular cuyo objetivo es reforzar los movimientos transversales interiores. Esta red facilitará en el futuro el acceso al centro de Madrid mediante las conexiones con líneas de Metro radiales y de tren. El Este es otra zona muy poblada y con pocos empleos, por lo que su población debe desplazarse a trabajar hacia otras zonas de la RMM, especialmente a la capital. En este caso, la opción ha sido ampliar una línea de Metro radial. La misma opción se ha aplicado en el Sudeste y el Norte, donde se ha producido un gran crecimiento de la población y de los empleos en la última década. Por último, en el Oeste, donde también se ha incrementado notablemente la población y el empleo, aunque la densidad es mucho menor, se ha optado por el Metro Ligero. Adicionalmente, se ha podido comprobar que el coste de construcción de esta última modalidad de transporte es $25 \%$ menor al del Metro convencional.

El análisis de la eficiencia de estas nuevas ampliaciones ha consistido en comprobar la demanda de las nuevas líneas en comparación con la red global de Metro. En todas ellas se ha incrementado la demanda en sus primeros años de funcionamiento, aunque esta expansión inicial se ha reducido a medio plazo hasta tener una evolución similar a la del conjunto de la red.

A partir de estos resultados, cabe plantear dos sugerencias generales para futuras investigaciones. La primera es el carácter político de las ampliaciones. La promoción del transporte público genera externalidades positivas vinculadas a la reducción del transporte privado, de la contaminación atmosférica y acústica y de los atascos de tráfico. No obstante, también produce beneficios políticos directos, ya que, desde 1995, el gobierno de la Comunidad de Madrid ha desarrollado planes de inversión cuatrienales en infraestructuras de transporte público, cuyas inauguraciones se producían precisamente en los meses previos a las elecciones. La utilización de estas ampliaciones como forma de reforzar el gobierno regional se combina con estrategias políticas en torno a los municipios hacia donde se dirigen las mismas (Cuadro 5). En este caso, la estrategia y las interacciones entre diferentes niveles políticos no son tan claras, al darse la posibilidad de favorecer a los municipios del mismo signo político para reforzar el poder del gobierno regional, o a los de signo contrario para desplazar al partido rival. Por otro lado, la reciente evolución de estas ampliaciones muestra el agotamiento de las nuevas inversiones. La última ampliación de 2011 ha sido muy limitada, con solo una nueva estación en un municipio de la periferia (Leganés), unas pocas estaciones en Madrid capital, y dos proyectos de tren -en Torrejón y en Móstoles-Navalcarnero- que se han retrasado. Los problemas financieros derivados de la crisis de los últimos años se han reflejado en esta reducción del impulso inversor, que deberá ser objeto de un análisis más detallado en futuras investigaciones. OEURE 


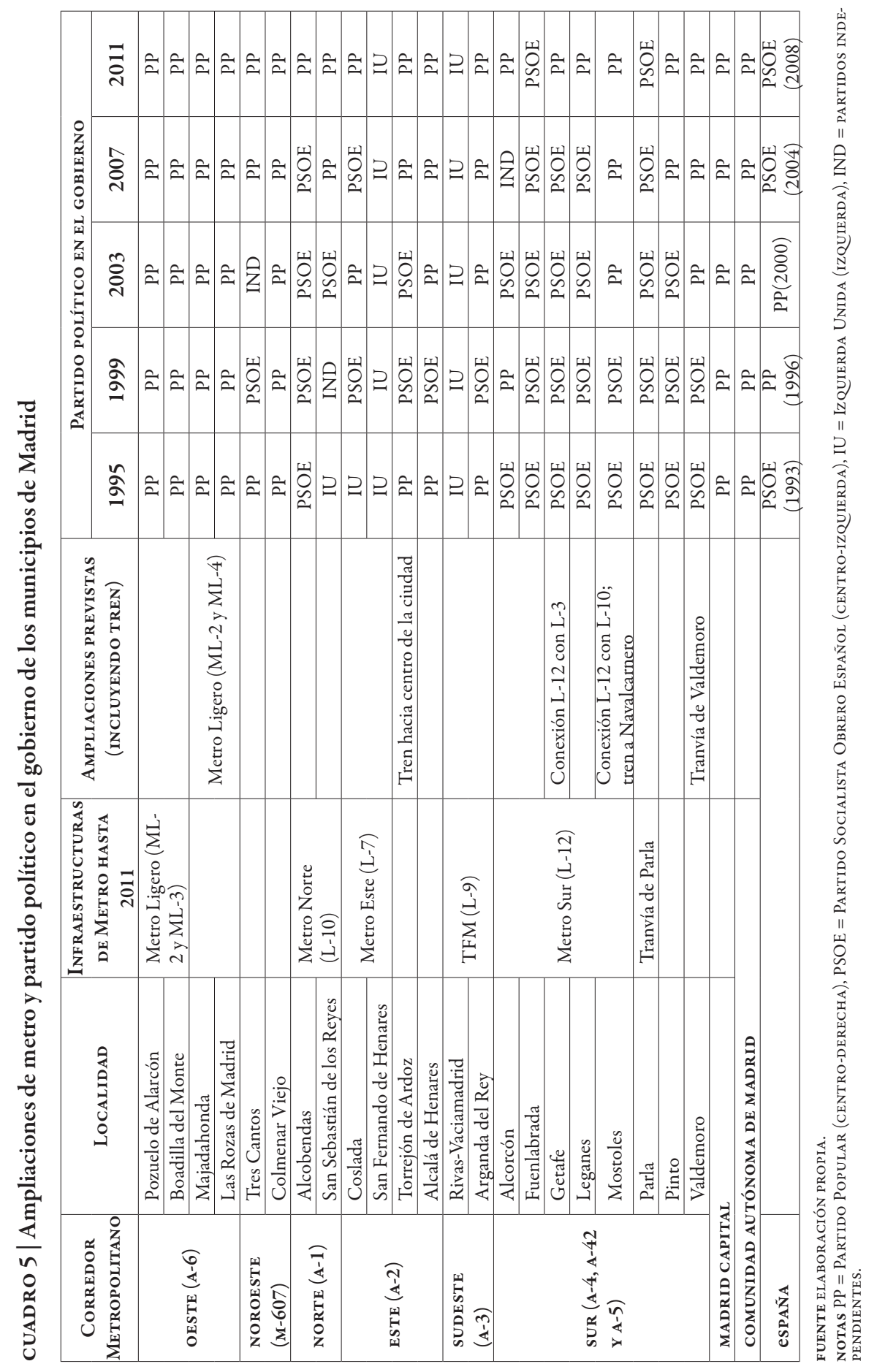




\section{Referencias bibliográficas}

Aguirre, C. \& Marmolejo, C. (2010). Hacia un método integrado de identificación de subcentros a escala municipal: un análisis para la región metropolitana de Barcelona. ACE: Architecture, City and Environment, 5(14), 99-122. Disponible en http://hdl.handle.net/2099/9347

Comunidad de Madrid (2010). Atlas de la Movilidad Residencia-Trabajo en la Comunidad de Madrid. Disponible en http://www.madrid.org/iestadis/fijas/estructu/general/territorio/atlasmovilidad 10. htm

Consejería de Transportes e Infraestructuras (2005). Ampliación del Metro de Madrid. Informe de la Consejería de Transportes e Infraestructuras, Madrid.

Consorcio Regional de Transportes (CRTM). (2009). Memoria del Consorcio Regional de Transportes Públicos Regulares de Madrid. Ejercicio 2009. Madrid: Autor.

Consorcio Regional de Transportes (CRTM). (2011). Demanda de transporte público colectivo en 2011. Madrid: Autor. Disponible en http://www.madrid.org/

European Metropolitan Transport Authorities (EMTA). (2009). Barometer of Public Transport in the European Metropolitan Areas. París: Autor.

Gallego, R. \& Pires, L. (2008). Análisis económico del Metro Ligero en la Comunidad de Madrid. Revista del Instituto de Estudios Económicos, 4, 323-370.

Gallo, M. T. \& Garrido, R. (2012). Una aproximación a la estructura urbana policéntrica en la Comunidad de Madrid. ACE: Architecture, City and Environment, 6(18), 69-100. Disponible en http://hdl.handle.net/2099/11682

Gallo, M. T., Garrido, R. \& Vivar, A. (2010). Cambios territoriales en la Comunidad de Madrid: policentrismo y dispersión. EURE, 36(107), 5-26. Disponible en http://www.eure.cl/wpcontent/uploads/2010/04/EURE_107_01_GALLO.pdf

Mella, J. M. \& López, A. (2006). Forma urbana y movilidad sostenible: el caso de Madrid. Revista del Instituto Estudios Económicos, 1-2, 158-189.

Méndez, R. (2007). El territorio de las nuevas economías metropolitanas. EURE, 33(100), 1-67. Disponible en http://www.scielo.cl/pdf/eure/v33n100/art04.pdf

Monzón, A. \& Hoz, D. (2006). Sostenibilidad y eficiencia económica del transporte en Madrid. Estudios Económicos. La movilidad y la eficiencia económica: especial aplicación a la ciudad de Madrid. Revista del Instituto de Estudios Económicos, 1-2.

Roca, J., Arellano, B. \& Moix, M. (2011). Estructura urbana, policentrismo y sprawl: los ejemplos de Madrid y Barcelona. Ciudad y Territorio. Estudios Territoriales, 43(168), 299-321. Texto, sin figuras, disponible en http://bit.ly/Z8ZFh2

Solís, E. (2008). Cambio de escala y estructura del nuevo territorio urbano madrileño: la región urbana policéntrica. En Coloquio Ibérico de Geografía (Alcalá de Henares - Pastrana), Actas del XI Coloquio Ibérico de Geografía, Asociación de Geógrafos Españoles, 2008, pp. 1-19.

UITP (Asociación Internacional de Transporte Público). (2005). Mobility in Cities Database. Bruselas: Autor. Disponible en http://www.uitp.org/publications/Mobility-in-Cities-Database. $\mathrm{cfm}$ 


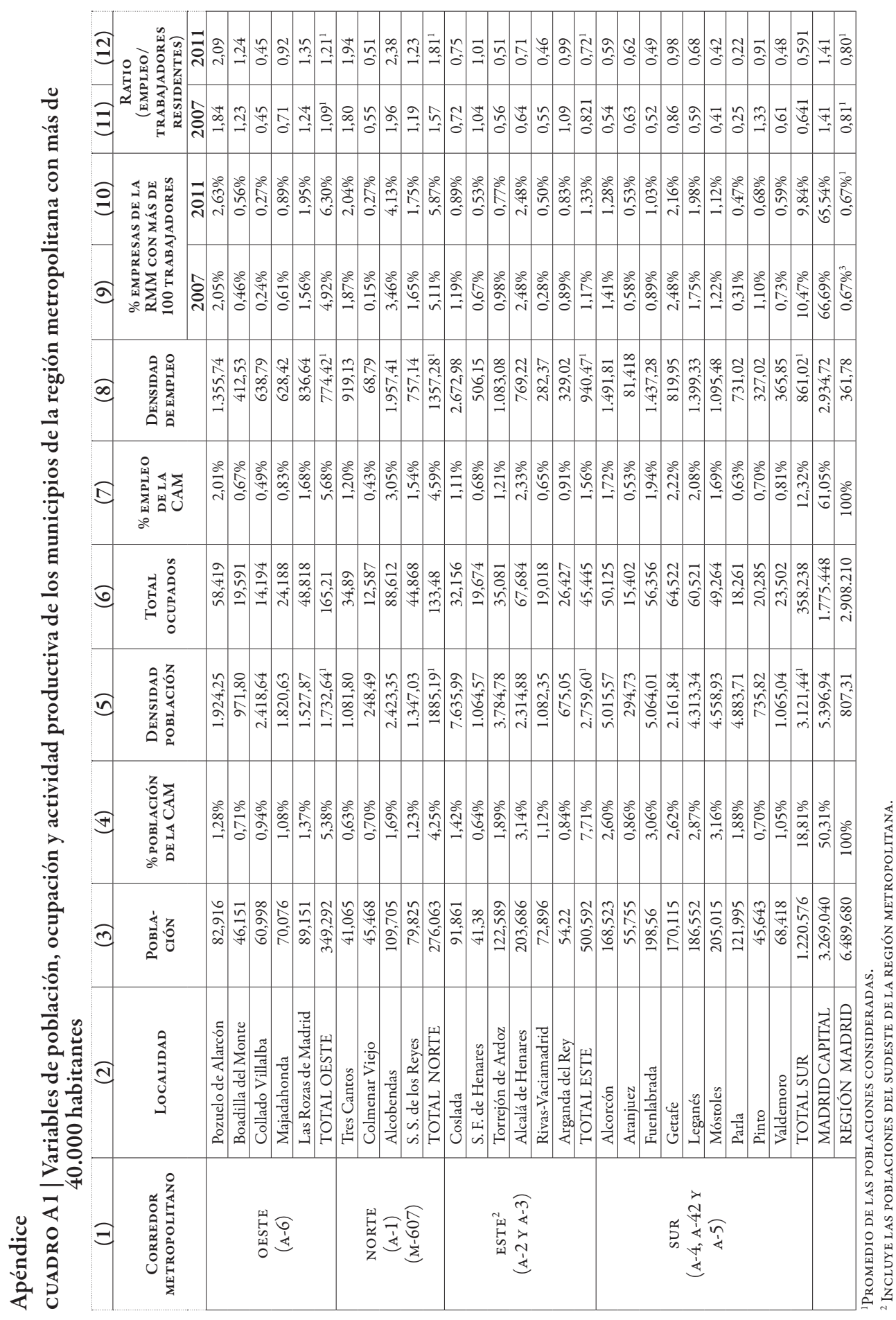

